\title{
Traditional Bone Setting: Analysis of Contribution and Patronage in Northern Ghana
}

\author{
Emmanuel Akiweley Wedam \\ Department of Development Studies \\ University for Development Studies, Wa Campus, Ghana \\ ewedam@uds.edu.gh \\ and \\ Samuel Twumasi Amoah \\ Department of Environment and Resource Studies \\ University for Development Studies, Wa Campus, Ghana \\ DOI//http://dx.doi.org/10.4314/gjds.v14i2.2
}

\begin{abstract}
Traditional bone setting (TBS) has made significant contributions in the area of primary health care and remains one of the oldest medical practices that numerous people in Africa patronise. This study examines TBS practice including patients' experiences and factors that influence people and patients' adoption decision. Using structured questionnaire and interviews, the study revealed how efficacy, quick services, nature of the bone injury as well as recommendations from families and friends who had ever visited a traditional bone setting practitioner significantly influenced the level of probability of adoption. However, though the cost of treatment and fast rate recovery had significant influence on adoption, they were not compelling enough in increasing the probability of adoption as compared to earlier-mentioned factors. The study concludes that in areas where allopathic medicine has failed, traditional bone setters have succeeded, there is therefore the need for proper recognition, investments and integration of this essential practice into modern health system especially in regions where health care infrastructure and staffing are inadequate.
\end{abstract}

Keywords: Traditional, Medicine, Bone Setting, Treatment, Adaptation

\section{Introduction}

Traditional bone setting (TBS) is a branch of traditional medicine which has deep roots in many countries across the world, although the art, practice and name may differ from region to region. In some regions of the world, TBS has and continuous to be the mainstay or alternative health care option for the population (Agarwal \& Agarwal, 2010). 
For instance, in India, China and Southern America the practice has become an integral part of the primary health care system and provides a vital medical support to people seeking orthopaedic medicine. It is estimated that about 10 to 40 percent of people in the world with dislocations and fractures are treated by traditional bone setters (WHO, 2014a; Agarwal \& Agarwal, 2010; Green, 1999). In India, traditional bone setters form the largest group of health care practitioners engaged in traditional medicine and there are nearly 70, ooo traditional bone setters in the country handling about 60 percent of trauma and trauma related cases (Agarwal \& Agarwal, 2010). Remarkably, albeit the practice is ancient, its popularity, acceptance and adoption is gaining more recognition among the international community now than any point in history.

In Africa, the practice of traditional bone setting subjugates the pre-colonial period and still continuous to play an essential role in health care delivery and services since the turn of the new millennium. The practice is very popular particularly, among the rural folk, and is usually the first option or point of call for the treatment of non-acute fractures and dislocations which may not require any urgent attention (GSS, 2010; MoH, 2006; Friedman, 2004; Onuminya, 2004; Quansah, Afukaar, \& Salifu, 2001). Many people also utilise this option when orthodox medicine fails. In spite of the fact that orthodox medicine has revolutionised the practice of medicine and how health care systems are structured in developing countries, traditional and complementary medicines have and continue to play a greater and a more diffused role in making health care affordable, accessible and available to many people in Africa.

In Ghana, the World Health Organisation reports that "most cases of bone fractures.... are treated by traditional bone practitioners using traditional medicines. In respect of curative services, the efficacy and potency of herbs are very real in traditional health services provisions" (WHO, 2014b:1). In most cases where orthodox bone specialists are absent, traditional bone setters have been the first points of call. Ironically, even though traditional bone setting has played and continuous to play a vital role in primary health care, there has been very little and in some cases no recognition of this feat (Peter, 2003; Nantulya \& Reich, 2002; Green, 1999; Museru, Leshabari, Grob, \& Lisokotala, 1998). According to Hag and Hag (2010), Onuminya (2006), Omeonu (2003), OlaOlorrun, Oladiran, Adeniran, (2001) studies and publications of traditional bone setting in West Africa are usually carried out by orthopaedic surgeons who usually focus on reporting the processes, methods and complications arising from traditional bone setting treatment. Again, although traditional bone setting treatment is an ancient act, its efficacy and safety is discussed mutely, with the focus mainly centred on treatment complications (Museru \& Mcharo, 2002; Horton, 2000; Ofiaeli, 1991). In Ghana, Arie"s, Marcel, Harry, Wegdam, and Sjaak, van der Geest (2007) reported that traditional bone setting is mostly ignored in publications on the state of medicine in the country. Only 
few studies have attempted to examine the factors that influence adoption as well as the experiences of patients. Yet, new figures from Ghana's Ministry of Health (MoH) show increasing rise in the practice and adoption of traditional bone setting in the country (MoH, 2015; MoH, 2014; Ventevogel, 1996). This suggests that traditional bone setting is still a fundamental aspect of Ghana's health care delivery system. In this paper, the authors explored the factors that influence the adoption of traditional bone treatment among rural and urban dwellers in northern Ghana and the experiences of patients' as well. The study is structured in four parts, the first and second parts contain the introduction and methodology of the study. The results and discussions of the study are contained in the third part of the study while the conclusion is contained in the fourth part of the study.

\section{Methodology}

\section{Study Design and Setting}

This is a mixed method study carried out over a period of three years from 2013 to 2016. A descriptive cross-sectional and a case study approach were adopted. Triangulation was applied in the process of data collection and analysis. This was necessary in order to enhance the validity of the data and the findings of the study. This study was conducted in Northern Ghana (see figure 1 for Northern Ghana). The area covers the three administrative regions of Upper West, Upper East and Northern region. The area lies approximately north of the lower section of the Black Volta. The area shares boundaries with Burkina Faso in the North, the Republic of Togo in the east and Cote d'Ivoire to the lower South-West. To the south, the area shares boundaries with the Brong Ahafo Region and the Volta Region (Awedoba, 2006). 


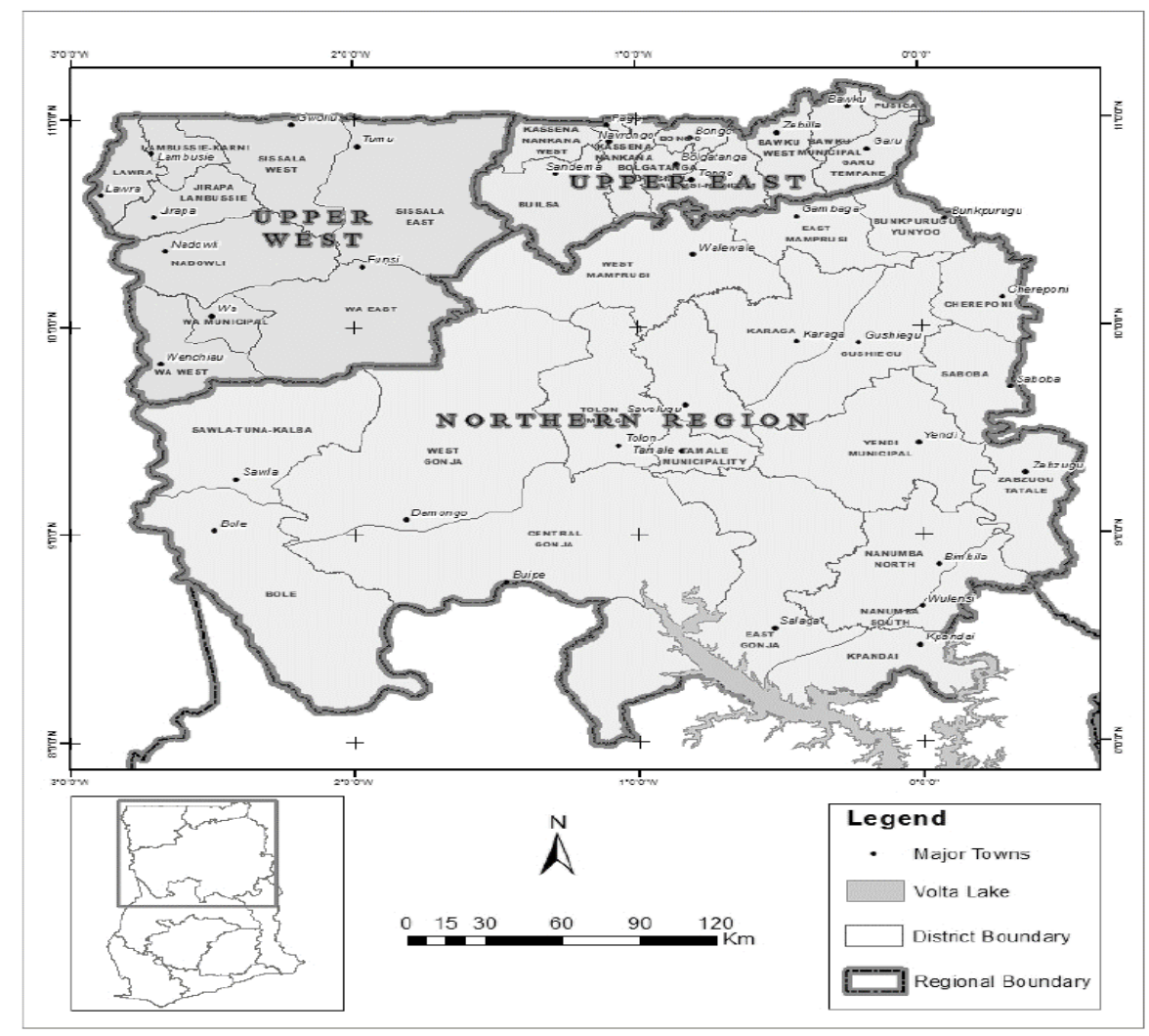

Figure 1: Study area

Source: Ghana Statistical Service, 2010

\section{Data Collection}

Data collection was done at three different levels. These levels were marked as level one, level two and level three. Level one consisted of data collected from four hundred and eight households. This data was collected from three different clusters and these were labelled as cluster one, cluster two and cluster three. One community representing a ward was purposively selected from all the three clusters. These communities were purposively chosen because of their heterogeneous nature. Each ward was further zoned in order to ensure a balance selection of respondents. From each zone in all the three wards, a total of 480 households/respondents scattered throughout the zones were systematically selected by relying on every third residential structure in every street using the probability-proportionate-to-size approach. (In all, 30 streets were identified). These households/respondents were selected based on the fact that they have never visited the hospital or a bone setting centre for the treatment of any bone related disorder. 
Level two of our data collection consisted of data collected from traditional bone setting centres in all the three clusters. A total of 27 major different bone setting centres were identified and selected throughout Northern Ghana (See table 1). Out of the 27 bone setting centres, 325 respondents were sampled for the study from a total population of 470. These respondents included "returnees", "leavers" and "arrivals". "Returnees" included respondents who left the bone setting centres to seek alternative treatment options elsewhere but returned later after their conditions got worse. "Leavers" were respondents who left the bone setting setters after they realised their conditions at the centres were getting worse and "arrivals" were respondents who were suffering from various injuries and had arrived at the centres for treatment. 
Table 1: Selected bone setting centres

\begin{tabular}{|c|c|c|}
\hline Bone Setting Centre & District Location & Regional Location \\
\hline Balawa & Wa & Upper West \\
\hline Jonga & Nadowli & Upper West \\
\hline Doung & Nadowli & Upper West \\
\hline Gwollu & Sissala West & Upper West \\
\hline Kpongu & $\mathrm{Wa}$ & Upper West \\
\hline Bihee & $\mathrm{Wa}$ & Upper West \\
\hline Nandom Tom & Nandom & Upper West \\
\hline Koro/Tanchara & Lawra & Upper West \\
\hline Nanton & Savelugu-Nanton & Northern \\
\hline Kalandei & East Gonja/Salaga & Northern \\
\hline Kulpi & East Gonja/Salaga & Northern \\
\hline Kakushe & East Gonja/Salaga & Northern \\
\hline Paansiya & Yenda & Northern \\
\hline Demong & Saboaba & Northern \\
\hline Naayilefong & Yendi & Northern \\
\hline Kukuo & Tamale & Northern \\
\hline Kpalba & Saboba & Northern \\
\hline Jakalayile & Tamale & Northern \\
\hline Tampion & Savulugu-nanton & Northern \\
\hline Daboya & West Gonja/Damango & Northern \\
\hline Wungu & West Mamprusi/Walewale & Northern \\
\hline Loagri & West Mamprusi/Walewale & Northern \\
\hline Saminie & East Mamprusi/Gambaga & Northern \\
\hline Gori & Bongo & Upper East \\
\hline Gunwoko & Kassena-Nankani & Upper East \\
\hline Kandiga & Kassena-Nankani & Upper East \\
\hline Nabango & Kassena-Nankani & Upper East \\
\hline
\end{tabular}

Source: Field Survey, 2015

The third level of data collection consisted of in-depth interviews with three traditional bone setting practitioners selected from the three separate clusters. In-depth interviews were also held with some fifteen patient respondents at this level. In order to achieve a good balance in our data collection and findings we employed a combination of several data collection tools and techniques. Questionnaire administration, in-depth interview 
schedules and observation were employed in the study. This was necessary in order to triangulate the data collected from the various sources and findings. Where necessary, questionnaires and interview questions were translated into native languages to give the respondents a clearer understanding of the questions in order to elicit the appropriate responses. Observation was employed in order to enable the researchers to among other things observe the nature of healing, the nature of services provided and the level of response of the patients to the treatment procedure. According to Rafkin and Pridmore (2001) and Yin (2009) this technique of data collection gives more direct information than other methods do.

\section{Participants Recruitment}

The participants in this study were also recruited at two levels. The first level included four hundred and eighty respondents selected from the three wards in each cluster. These respondents were both males and females from all the four hundred and eight households selected. The respondents were purposively sampled based on age criteria (More than eighteen years) and questionnaires administered to them.

The second level of respondents were selected through a patient criterion from twentyseven bone setting centres in all the three clusters. These respondents (patients) also included males and females and were selected through a simple random sampling procedure. In order to achieve a fair balance in the sample distribution, patient characteristics such as their demographic information, bio-data and medical history were not considered in the criteria for the selection of the respondents. These criteria were not also considered in the selection of respondents for the questionnaire administration. On the other hand, fifteen patient respondents and three traditional bone setting practitioners who were selected for the in-depth interview were however selected based on their knowledge, experience, medical history and demographic characteristics.

\section{Participants Information}

In order to better understand and appreciate the characteristics of the respondents in the research, the research team spent a period of three years collecting patient respondent information and household respondent information. Household respondents included people who had never visited a traditional bone setting centre before. Special numbers were written on the houses of the household respondents that participated in the study. We also developed special codes for all the household respondents in the study. This made it easy to re-contact any participant or household for additional information where necessary. Only household respondents who were 
eighteen years and above were selected to participate in this research (See table 2 for details).

Table 2: Summary of household respondents in the study

\begin{tabular}{|l|l|l|l|}
\hline Cluster & Ward & $\begin{array}{l}\text { No-of sampled } \\
\text { respondents }\end{array}$ & Criteria in years \\
\hline Upper East Region (C.1) & Bolgatanga (W. 1) & 160 & $18+$ \\
\hline Upper West Region (C.2) & Wa (W. 2) & 160 & $18+$ \\
\hline Northern Region (C.3) & Tamale (W.3) & 160 & $18+$ \\
\hline
\end{tabular}

Source: Field Survey, 2015. C = Cluster W = Ward

In the case of the respondents who were patients, both OPD and IPD information were collected within the research period throughout all the twenty-seven bone setting centres using a special notebook designed by the research team. This exercise was directly carried out by trained community members within the bone setting centres and supervised by three of the main research team members. The notebook was used to record patient information such as age, sex/gender, occupation, educational background and the type of bone disorder. Special identification numbers were given to the patients upon arrival at the various centres, and each patient maintained the same number till the patient left the centre. A special folder was also kept for each of the patients till they left the centres. This folder was designed by the research team and was meant to keep records of the patients while on admission at the centres. The folder captured information on the time spent by each patient before leaving the centres; the nature of the condition of the patient upon arrival at the centre, patient type that is, whether patient was a "Leaver", "Returnee" or an "Arrival". Table three shows a summary of the respondents' information as captured by our records. 
Table 3: Summary of patient respondent's information

\begin{tabular}{|c|c|c|c|c|c|c|c|c|c|c|c|c|c|c|c|c|c|}
\hline \multirow[t]{2}{*}{$\begin{array}{l}\text { Age } \\
\text { Group }\end{array}$} & \multirow[t]{2}{*}{ No. } & \multicolumn{2}{|c|}{ Sex } & \multirow{2}{*}{\multicolumn{2}{|c|}{$\begin{array}{l}\text { Occupation/ } \\
\text { Designation } \\
\text { 1-6 mth }\end{array}$}} & \multicolumn{3}{|c|}{ Time Spent } & \multicolumn{2}{|c|}{ 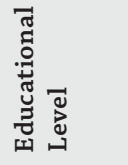 } & \multicolumn{2}{|c|}{ 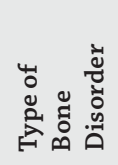 } & \multicolumn{2}{|c|}{ 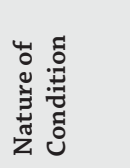 } & \multicolumn{3}{|c|}{ 范 } \\
\hline & & 山 & $\sum$ & & & 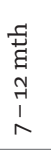 & 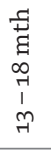 & $\begin{array}{l}\tilde{j} \\
\text { D } \\
0 \\
z\end{array}$ & '્ડ่ં & 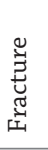 & 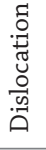 & ڤँ & 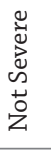 & $\stackrel{0}{5}$ & بـ & $\sum_{5}^{*}$ & \\
\hline $1-20$ & 28 & 4 & 24 & M & 42 & 214 & 103 & 8 & 206 & 119 & 233 & 92 & 203 & 122 & 76 & 12 & 237 \\
\hline $21-40$ & 243 & 23 & 220 & F & 91 & & & & & & & & & & & & \\
\hline $40+$ & 54 & 17 & 37 & $\mathrm{BS} / \mathrm{W}$ & 13 & & & & & & & & & & & & \\
\hline & & & & ST/P & 13 & & & & & & & & & & & & \\
\hline & & & & C/P.S & 11 & & & & & & & & & & & & \\
\hline & & & & $\mathrm{T}$ & 16 & & & & & & & & & & & & \\
\hline & & & & Trad & 79 & & & & & & & & & & & & \\
\hline & & & & $\mathrm{D} / \mathrm{DM}$ & 57 & & & & & & & & & & & & \\
\hline & & & & Oth & 3 & & & & & & & & & & & & \\
\hline
\end{tabular}

Source: Field Survey, 2015

NOTE: Occupation/Designation: $\mathrm{M}=$ Mining $\mathrm{F}=$ Farming BS/W = Blacksmith/Welders C $/$ P.S $=$ Civil Servant $\mathrm{T}=$ Teacher Trad $=$ Trader $\mathrm{D} / \mathrm{DM}=$ Driver $/$ Drivers Mate Oth $=$ Others

Sex: $\mathrm{F}=$ Females $\mathrm{M}=$ Males

Patient Type: "L" = Leavers "R" = Returnees "A" = Arrivals 


\section{Data Analysis}

Two different test or analyses were carried out in this study; a binary logistic analysis and a one sample T-test analysis. The binary logistic regression was used to build a model for "household respondents" that is respondents who had never visited a hospital or bone setting centre for any bone related treatment. We adopted this analysis approach because our dependent variable was a dichotomous variable (Will you adopt traditional bone setting treatment? $1=$ Yes, 2 = No). Our test of significance was measured using a $p$-value of $p \leq 0.05, p \leq 0.01, p \leq 0.001$ for our model and independent variables. The probability of adopting traditional bone setting treatment for our binary logistic regression model is expressed as,

$$
P\left(Y_{i}=1\right)=P_{i}=\frac{1}{1+\exp ^{-z}}
$$

This can be operationalized as;

$\operatorname{Logit} P\left(Y_{i}^{*}\right)=\beta_{0}+\sum_{i=1}^{n} \beta_{i} X_{i}+\varepsilon_{i}$

Thus, the binary logit regression model was expressed as;

$Y($ Adopt $=1)=\beta_{0}+\beta_{1} \cdot \operatorname{sexh}_{i}+\beta_{2} \cdot \operatorname{cost}_{i}+\beta_{3}$ eduhh $_{i}+\beta_{4}$ fearamputation $_{i}+$ $\beta_{5}$. efficacy $+\beta_{6}$. quick recovery ${ }_{i}+\beta_{7}$. quickservices ${ }_{i}+\beta_{8}$.religion ${ }_{i}+\beta_{9 .}$.distance/ convenience $_{i}+\beta_{10 .}$.naturejuiry/loc $i+\varepsilon_{i}$

$Y_{i}^{*}=$ a latent variable representing the propensity of a person/respondent $i$ to adopt traditional bone setting treatment ( 1 if person/respondent adopt, and 2 otherwise)

$\beta_{\mathrm{o}}=\mathrm{a}$ constant term

$X_{i}=\mathrm{K}=$ the vector of person/respondents characteristics variable that influence adoption decision (Set of variables explaining the adoption decision including respondent's choice of traditional bone setting)

$\beta_{i}=$ parameters to be estimated

$\operatorname{Exp}\left(\beta_{i}\right)$ indicates the odd ratio for a person/respondent having characteristics $i$ versus not having $i$

$\varepsilon_{i}=$ error term of the $i^{\text {th }}$ person/respondent

$\mathrm{i}=1,2,3 \ldots \mathrm{n}$ person/respondent. 
The one sample $\mathrm{T}$ - test was used to measure the level of association of two independent variables to a dependent variable. This was applied to respondents (patient respondents) who had ever adopted traditional bone setting treatment before. The $p$-value for test of significance for the one sample-T test was also measured using $p$-values of $p \leq 0.05, p \leq$ 0.01 , and $p \leq 0.001$.

\section{Dependent Variables}

There were two dependent variables (2 dependent for binary and 1 dependent for one sample T-test) in this study. Both dependent variables were treated or handled separately because they had different characteristics and effect. The dependent variable for the binary analysis was a dichotomous variable ( $1=$ Yes, 2 = No) while the dependent variable for the one sample T-test was not a dichotomous variable (1=Yes).

\section{Independent Variables}

Two different independent variables were also used in this study. In the case of the binary logistic regression, there were ten predictors or independent variables included in the analysis. These predictors were respondents sex, cost of traditional bone setting treatment, educational attainment of respondents, fear of amputation, efficacy of treatment, rate (quick) recovery, speed with which services were delivered (quick services), respondents religion, convenience or distance of bone setting centres and the nature/location of the injury or disorder. Conversely, the independent variables for the one sample T-test were two: that is, recommendation by someone and previous experience of the guest medical tourist (Ever visited).

\section{Results and Discussions}

Common cases of bone dislocations recorded were shoulder, wrist and kneecap dislocations. These were the cases recorded at the time of this studied. Humerus, shin bone and femur fractures were also the common cases of bone fractures recorded. In all, a total of 325 cases were recorded and these consisted of ninety-two cases of bone dislocations and two hundred and thirty-three cases of bone fractures. Even though more people reported bone fracture cases than cases of bone dislocation, the common causes of the various bone disorders were mostly motor vehicle and motor bike accidents. Generally, shin bone and humerus cases were the most reported bone cases in all the twenty-seven bone centres that were visited, while ankle and finger cases were also the least number of bone cases and were rarely recorded at the centres ( See table 4 for details). 
Table 4: Bone disorders recorded at bone setting centres

\begin{tabular}{|c|c|c|c|c|c|}
\hline $\begin{array}{l}\text { Bone } \\
\text { Disorder }\end{array}$ & Specific Area & $\begin{array}{l}\text { Actual Number } \\
\text { of Patients }\end{array}$ & \% Fractures & \% Dislocations & Rank \\
\hline \multirow[t]{8}{*}{ Dislocations } & Shoulder & 41 & & 44.5 & $1^{\text {st }}$ \\
\hline & Wrist & 18 & & $19 \cdot 5$ & $2^{\text {rd }}$ \\
\hline & Elbow & 11 & & 11.9 & $4^{\text {th }}$ \\
\hline & Hip & 3 & & 3.2 & $5^{\text {th }}$ \\
\hline & Neck & 2 & & 2.1 & $6^{\text {th }}$ \\
\hline & Ankle & 1 & & 1.0 & $7^{\text {nd }}$ \\
\hline & Kneecap & 15 & & 16.3 & $3^{\text {rd }}$ \\
\hline & Fingers & 1 & & 1.0 & $7^{\mathrm{rd}}$ \\
\hline Total & & 92 & & $100 \%$ & \\
\hline \multirow[t]{6}{*}{ Fractures } & Humerus & 82 & 35.1 & & $1^{\text {st }}$ \\
\hline & Tabia/shin bone & 42 & 18.0 & & $2^{\text {nd }}$ \\
\hline & Thigh bone/Femur & 33 & 14.1 & & $4^{\text {th }}$ \\
\hline & Fibula & 19 & 8.1 & & $5^{\text {th }}$ \\
\hline & Radius & 19 & 8.1 & & $5^{\text {th }}$ \\
\hline & Ulna & 38 & 16.3 & & $3^{\text {th }}$ \\
\hline Total & & $233+92=325$ & $100 \%$ & & \\
\hline
\end{tabular}

Source: Field Survey, 2015

\section{Determinants of Traditional Bone Setting Treatment (Household Respondents)}

The presentation in this section is captured in two parts. The first section presents the results of binary logistic regression analysis while the second part presents the results for one sample T-test analysis. Responses from four hundred and eighty household respondents were included in the binary logistic analysis. All the independent variables/ predictors were included in the logistic regression analysis since all the variables were significant at $\mathrm{p} \leq 0.05$. Ten independent variables were measured in order to determine their level of significance/association in the adoption of traditional bone setting for the treatment of bone related disorders. The independent variables were carefully selected in a manner that the variables reflected exactly the reasons why people would opt for traditional bone setting treatment. In doing this, a preliminary survey was carried out to determine the reasons why people will adopt traditional bone setting treatment. At the end of the preliminary survey, various reasons were obtained but these were grouped and classified into ten major reasons; these make up the independent variables. These variables were educational attainment, sex, religion, cost, distance, efficacy, quick recovery, quick services, fear of amputation and the nature/location of the injury. 
There were no missing variables/values in the sample data as well as the output of the logistic regression analysis. The significance test for the regression model was 314.532 with ten degrees of freedom at a p-value of o.oo. This shows the fitness of the model and means that the logistic model is significant at $\mathrm{p}$-value of 0.00 (Estimated significant limit for model $\mathrm{p} \leq 0.05$ ). The -2 Log Likelihood statistic of the model is 101.531; ( $2 \mathrm{R}^{2}$ is .481 and .829). This also shows how strong the model predicts the predictor variables. The predictive power of our model is high for an overall success rate of 96.3 percent. The area under the ROC curve is .794 with 95 percent confidence interval $(.683,704)$. Again, the area under the curve is significantly different from 0.05 since the p-value is .ooo meaning that our logistic regression model categorises the group in the sample significantly better rather than by random.

Table 5: Logistic regression for predictors in logistic analysis

\begin{tabular}{|l|l|l|l|l|l|l|l|l|}
\hline Predictors & Co-efficient & $\begin{array}{l}\text { Std. } \\
\text { Err. }\end{array}$ & Wald & $d f$ & $\begin{array}{l}p- \\
\text { value }\end{array}$ & $\begin{array}{l}\text { Odds- } \\
\text { Ratio }\end{array}$ & \multicolumn{2}{l|}{$95 \%$ C.I } \\
\hline Education & .838 & .723 & 1.342 & 1 & .247 & 2.311 & .560 & 9.536 \\
\hline Religion & 1.310 & .716 & 3.352 & 1 & .067 & 3.706 & .912 & 15.063 \\
\hline Gender & 1.767 & .673 & 6.891 & 1 & .09 & 5.850 & 1.564 & 21.878 \\
\hline Cost & -2.978 & 1.169 & 6.490 & 1 & .011 & $.051^{* *}$ & .005 & .503 \\
\hline Distance & 3.479 & 1.978 & 3.095 & 1 & .079 & 32.428 & .672 & 1563.918 \\
\hline Efficacy & 4.221 & .942 & 20.064 & 1 & .000 & $68.083^{* * *}$ & 10.739 & 431.628 \\
\hline Quick recovery & -3.129 & .900 & 12.086 & 1 & .001 & $.044^{* *}$ & .008 & .255 \\
\hline Quick service & 4.584 & .842 & 29.641 & 1 & .000 & $97.946^{* * *}$ & 18.803 & 510.195 \\
\hline Fear of amputation & 1.125 & 1.009 & 1.242 & 1 & .265 & 3.079 & .426 & 22.261 \\
\hline Nature of injury & 3.517 & .801 & 19.278 & 1 & .000 & $33.687^{* * *}$ & 7.008 & 161.926 \\
\hline Constant & -23.492 & 4.885 & 23.124 & 1 & .000 & $.000^{* * *}$ & & \\
\hline
\end{tabular}

Source: Field Survey, 2016

Omnibus Tests of Model Coefficients: Model Chi-Square statistic $=314.532$ where $d f=10$ and probability $<0.001(0.00)$

Total number of respondents $=480 *$ significant $(0.01<\mathrm{p} \leq 0.05)^{* *}$ highly significant $(\mathrm{p} \leq$ o.01) ${ }^{* * *}$ very highly significant $(\mathrm{p} \leq 0.001)$ 
The study revealed that while some of the variables in the distribution showed very high significance with the adoption of traditional bone setting; others showed less significance and no significance at all (see table 4). Five variables in the sample distribution that is educational background $(p>0.05)$, sex $(p>0.05)$, religion $(p>0.05)$, distance ( $p>0.05$ ), and fear of amputation ( $p>0.05$ ) showed no statistical significance at all in the adoption of traditional bone setting. The significance levels of these variables were all more than our estimated $p$-value of $p \leq 0.05$. This indicates that there is no probability that a person's educational background, sex, religion, distance to the bone setting centre/s, fear of amputation if a patient visits the hospital for treatment influences a person's choice or decision to adopt traditional bone setting treatment. The other variables (cost, efficacy, quick recovery, quick services and nature of injury) however, showed varied degrees of significance in the adoption of traditional bone setting treatment. The findings revealed that the cost of traditional bone treatment $(\mathrm{p}$ $=.011)$ and quick recovery $(\mathrm{p}<.001)$ exhibited highly statistical significance levels. There is a $0.051^{* *}(0.005 ; 0.503)$ probability of cost and a $0.044^{* *}(.008 ; .255)$ probability of quick recovery in the adoption of traditional bone setting treatment. This indicate that people have a $0.051^{* *}(0.005 ; 0.503)$ chance of opting for traditional bone setting treatment based on cost and a $0.044^{* *}$ (oo8; 0.255) chance of choosing traditional bone setting treatment based on how quick the recovery will be.

The logistic regression also indicates that the probability of adaptation for three of the predictor variables efficacy, quick services and the nature/location of the bone injury were very highly statistically significant $(p \leq 0.001)$. Efficacy of treatment $(p \leq 0.001)$, quick services provided at bone setting centres $(p \leq 0.001)$ and the nature/location of the bone injury ( $\mathrm{p} \leq \mathrm{0.001)}$ all showed a very strong relation/influence on the adoption of traditional bone setting treatment (See table 4). The odds-ratios for these three predictor variables (efficacy, quick services and nature of injury) indicate that there is $97.946^{* * *}$ (18.803; 510.195) probability that people will opt for traditional bone setting treatment due to its efficacy, and about $68.083^{* * *}(10.739 ; 431.628)$ and $33.687^{* * *}(7.008 ; 161.926)$ probability that this will be due to the quick services provided at the treatment centres and the nature/location of the injury respectively.

A unit increase in cost of treatment would see a 0.051 percent increase in the likelihood of adoption of traditional bone setting treatment. This means that even though cost is a highly significant predictor in adoption, a unit increase in the cost of treatment by bone setting practitioners will not lead to a reduction in adoption but rather an increase. This means people are influenced by other factors beyond the cost of the service. On the other hand, the odds-ratio for the logistic regression indicates that a unit increase in the services provided by traditional bone setting practitioners at bone setting centres could drastically lead to a 68.1 percent increase in the likelihood of people adopting. 


\section{Perspectives of Patient Respondents}

This section presents the results for the determinants of traditional bone setting treatment for patient respondents from all the twenty-seven bone setting centres that were included in the research. Due to the fact that these patients had or were already adopting traditional bone setting treatment, it was appropriate for the study to adopt a different statistical test/analysis. In order to sufficiently address this, the applied a one sample T-test/analysis to measure why these patients (Patient respondents) opted for traditional bone setting treatment. Two main predictors were considered in the sample distribution for this test/analysis that is "ever visited" and "recommended by someone". These predictors were considered after the patients were interviewed and asked why they opted for traditional bone setting treatment. Three hundred and twentyfive patient respondents were included in this analysis and there were no missing values/ variables in the sample distribution (see table 6 below for test results).

Table 6: One-sample $T$ test for predictors' means test for patient respondents

\begin{tabular}{|l|l|l|l|l|}
\hline Predictors & $T$ & $d f$ & $p$-value & Mean Difference \\
\hline Ever visited & $72.013^{* * *}$ & 324 & .000 & 1.745 \\
\hline Recommended by someone & $50.981^{* * *}$ & 324 & .000 & 1.357 \\
\hline
\end{tabular}

Source: Field Survey, 2016

$\mathrm{N}=325^{*}$ significant $(0.01<\mathrm{p} \leq 0.05)^{* *}$ highly significant $(\mathrm{p} \leq 0.01)^{* * *}$ very highly significant $(\mathrm{p} \leq 0.001)$

The test analysis revealed that the two predictors for the patient respondent analysis were very highly significant $\left(\mathrm{p} \leq 0.001^{* * *}\right)$. Friends, relations and close associates ( $\mathrm{p}$ $\leq 0^{\left.0.001^{* *}\right)}$ have a very high influence/significance on a person's decision/choice to adopt traditional bone setting treatment. Similarly, patients who have ever visited $\left(\mathrm{p} \leq 0.001^{* * *}\right)$ a traditional bone setting centre before for treatment have a very high probability of revisiting again. The analysis revealed that this was mainly influenced by the significant predictors in our logistic regression that is cost, efficacy, quick recovery, quick services and the nature of the injury. However, quick services ( $\mathrm{p} \leq 0.001^{* * *}$ ), nature of the injury ( $\left.\mathrm{p} \leq 0.001^{* * *}\right)$ and efficacy of treatment $\left(\mathrm{p} \leq 0.001^{* * *}\right)$ were most likely to influence such persons (Old patients) than cost ( $\left.\mathrm{p} \leq 0.01^{* *}\right)$, and quick recovery ( $\mathrm{p}$ $\left.\leq 0.01^{* *}\right)$. This is also true for persons who visited the traditional bone setting centres based on recommendation from a friend/friends, family relations and close associates:

\section{Respondent 6 explained:}

I was first admitted at the Akomfo Anokye Teaching Hospital in Kumasi, but after some days, my condition deteriorated and got even worse. My case became hopeless and I was virtually a dead man; you know what I mean.... 
But my family later brought me here and as you can see, my condition has drastically improved. With little help, I can stand, sit and move my body. -32 years old commercial driver - male patient.

The respondents who had ever visited traditional bone setting centres before were likely to go back based on their last experience and level of satisfaction:

Respondent 1 revealed: "I have been here before and I have also seen people who have been here for treatment and they have been healed very well... the people (here) produce good results." - 33 year old miner - male patient.

Recommendations from friends, family members and close associates were made mainly based on the significant predictors in our logistic regression that is, the cost of treatment, the efficacy of treatment, quick recovery, quick services provided at the traditional bone treatment centres and the nature of the injury but more significantly efficacy, quick services and the nature of the injury usually ranked highest: Respondent 1 opined: "Prior to my accident I sent my son who had a broken arm to the hospital and they put POP on him. When he got healed, his leg was stiff... I don't want my leg to suffer the same fate that is why I came here." -67 year old farmer - male patient.

This shows one of the reasons why people put premium on traditional bone setting treatment as compared to hospital treatment.

Traditional bone setting practitioners have and continue to play a significant role in Ghana's health care delivery particularly, in the area of primary health care (Arie"s, et. al. 2007; WHO, 2002; WHO, 2001; MoH, 2000; Onuminya, et. al. 1999; Castot, 1997; Chan, 1997; World Bank, 1993). Bone fractures and dislocations are usually treated by traditional bonesetters, whose skills and services have been praised not only by their clients but by many. This study revealed that about 80.1 percent of people (household respondents) say they will choose traditional bone setting treatment over orthodox medical treatment. This finding confirms the findings of the UNDP (2007) Human Development Report 2007, which states that about 80 percent of Ghanaians rely on traditional medicine for primary health care. This is based on the fact that the service is cheaper, accessible, affordable, flexible, available, acceptable, and convenient or people simply believe it is more effective (World Bank, 2008; WHO, 2008; VOA News, 2006; Goldman and Kennedy, 1998). For people who are poor, the cost of modern surgery could be quite expensive to bear and as such will be influenced by the fact that traditional bone setting treatment is cheaper.

There have also been a lot of criticisms about the efficacy, safety, skills, experience and the service delivery of traditional bone setters and traditional bone treatment. Hag and Hag (2010) have described traditional bone setters as quacks who have no skills and 
rely on trial and error methods in their operations. According to Hag and Hag (2010), Onuminya (2006), Omeonu (2003), OlaOlorun et. al. (2001) their operations usually lead to serious complications and as a result people who opt for traditional bone setting treatment later get dissatisfied with the results. The findings in this research however contest these claims since efficacy of treatment is one of the strongest reasons why people are more likely to choose traditional bone setting treatment.

\section{Conclusion}

For the purposes of policy and planning, two fundamental issues are highlighted. In Ghana, the lack of health infrastructure, high cost of health care and the shortage of physicians especially, in some rural communities clearly show that health planners and policy makers need to critically consider how integration of traditional bone setting treatment and orthodox medicine can be mutually possible. Mainstreaming traditional bone setting treatment into conventional orthodox medicine practice will require a lot of political and legal space manoeuvrings due to rivalry, suspicions and the raging debate about superiority, but this is still possible if only policy makers can properly locate the major entry points.

According to the World Health Organisation, the practice of traditional bone setting is common in Ghana and widely available for the whole population (WHO, 2002). As a result, this could be the major starting point for addressing both technological and health care gaps in Ghana. Health planners and policy makers need to design and formulate policies within the framework of health care utilisation and treatment strategies that works for people particularly, people in rural and underserved communities where medical infrastructure and staffing is in critical shortfall. This can be the first step towards making the practice of traditional bone setting more attractive and acceptable to attract the right investments, attention and cooperation.

People patronise traditional bone setting treatment not only because it's cheaper and convenient but precisely because it works. Therefore, an appropriate integration is necessary in order to monitor, control, regulate and promote the practice of traditional bone setting in Ghana (See Mensah et. al., 2005). This is essential because the practice has made significant contributions in the area of primary health care and health care penetration in Ghana. 


\section{References}

Agarwal, A. and Agarwal, (2010). The practice and tradition of bone setting. Education for Health, 23(1), pp. 1-8.

Arie“s, H. Marcel, J. Harry, H. Wegdam, and Sjaak, van der Geest. (2007). Fracture treatment by bonesetters in central Ghana: patients explain their choices and experiences. Tropical medicine and international health, pp. 564-574. Blackwell Publishing Ltd.

Awedoba, (2006). The peoples of northern Ghana. National commission on culture. www. ghanaculture.gov.gh. Available at; 24th November, 2016.

Castot, A. Djezzar, S. Deleau, N. Guillot, B. and Efthymiou, L. (1997). Drug surveillance of herbal medicines Thérapie, 52, pp. 97-103 (in French.).

Chan, T. (1997). Monitoring the safety of herbal medicines. Drug Safety, 17, pp. 209-215.

Friedman, E. (2004). An action plan to prevent brain drain: building equitable health systems in Africa. Report by physicians for human rights, Cambridge, MA, USA.

Ghana Statistical Service, (2010). National housing and population census report, Accra, Ghana Statistical Service.

Goldman, S. and Kennedy, D. (1998). FDA's medical products reporting program. A joint effort toward improved public health. Pub. Med., 103, pp. 13-16

Green, S. (1999). Orthopaedic surgeons: inheritors of tradition. Clinical Orthopaedics and Related Research 363, pp. 258-263.

Hag, and Hag, (2010). Complications in fractures treated by traditional bonesetters in Khartoum, Sudan. Khartoum Medical Journal, 3(1), pp. 401-405.

Horton, R. (2001). Ghana: defining the African challenge. The Lancet 358, pp. 2141-2149.

Ibrahim, A. Kazeem A and Mercy, A. (2011). Herbal medicine use among urban residents in Lagos, Nigeria. BMC Complementary and Alternative Medicine.

Ministry of Health, (2000). Medium term health strategy towards Vision 2020. Ministry of Health, Accra.

Ministry of Health, (2006). Traditional and modern health care: Partnership for the future: A Report on national consensus. Ministry of Health, Accra.

Ministry of Health, (2015). The state of health services in Ghana. Annual report of the ministry of Health. Ghana.

Museru, L. and Mcharo, C. (2002). The dilemma of fracture treatment in developing countries. International Orthopaedics 26, pp. 324-327. 
Museru, M, Leshabari, T. Grob, U. and Lisokotala, M. (1998). The pattern of injured patients seen in the orthopaedic and trauma wards at Muhimbili Medical Centre Dar es Salaam. East and Central African. Journal of Surgery 5, pp. 15-21.

Nantulya, M, and Reich M. (2002). The neglected epidemic: road traffic injuries in developing countries. British Medical Journal, 324, pp. 1139-1141.

Ofiaeli, O. (1991). Complications of methods of fracture treatments used by traditional healers: a report of three cases necessitating amputation at Ihiala, Nigeria. Tropical Doctor, 21, pp. 182-183.

OlaOlorrun, D. Oladiran, O. Adeniran, A. (2001). Complications of fracture treatment by traditional bonesetters in southwest Nigeria. Family Practice, 18(6), pp. 635-637.

Omeonu, S. (2003). Long bone fracture techniques: A Nigerian experience. The Nigerian Journal of General Practice, 7(3), pp. 1-5.

Onuminya, J. (2004). The role of the traditional bonesetter in primary fracture care in Nigeria. South African Medical Journal, 94, pp. 652-658.

Onuminya, J. (2006). Performance of a trained traditional bonesetter in primary fracture care. South Africa Medical Journal, 94(8), pp. 652-658.

Onuminya, J. Onabowale, B. Obepka, P. and Ihezue, C. (1999). Traditional bone setter's gangrene. International Orthopaedics 23, pp. 111-112

Peter, 0. (2003). Current ethical and other problems in the practice of African traditional medicine. Journal of Medicine and Law, 22(1), pp. 29-38.

Quansah, E. Afukaar, F. and Salifu, M. (2001). Casualty trends in road traffic accidents. Ghana Medical Journal 35, pp. 4-7.

Rifkin, S. and Pridome, P. (2001). Partners in Planning: Information, Participation and Empowerment. Macmillan Publishers Limited.

UNDP, (2007). Human Development Report 2007. United Nations' Development Programme.

Ventevogel, P. (1996). Whiteman's things: training and detraining healers in Ghana. Het Spinhuis, Amsterdam.

VOA News, (2006). Working to modernize traditional health medicine. Available: VOAnewsonline.Com. September 22, 2006. Accra.

WHO, (2000). General guidelines for methodologies on research and evaluation of traditional medicine. Geneva: WHO.

WHO, (2001). Legal status of traditional medicine and complementary/alternative medicine: A worldwide Review. Geneva; WHO. 
WHO, (2002). WHO traditional medicine strategy 2002-2005, Geneva: WHO.

WHO, (2002). World health report. Traditional medicines strategy 2002-2005. WHO, Geneva.

WHO, (2008). WHO congress on traditional medicine. Beijing, China. WHO. Geneva.

WHO, (2014). World health statistics. WHO Press, WHO, 20 Avenue Appia, 1211 Geneva 27, Switzerland.

WHO, (2014a). Atlas of African Health Statistics 2014. Health situation analysis of the African Region. World Health Organization. Regional Office for Africa.

WHO, (2014b). WHO guidelines on safety monitoring of herbal medicines in pharmacovigilance systems. World Health Organization Geneva.

World Bank, (1993). World development report: investing in health. New York: Oxford University Press.

Yin, R. (2009). Case study research: Design and methods. London: Sage. 